\title{
NILAI-NILAI KEHIDUPAN PADA NOVEL MOGA BUNDA DISAYANG ALLAH KARYA TERE LIYE
}

\author{
Lozi Septiana ${ }^{1}$, Yayah Chanafiah ${ }^{2}$, dan Amril Canrhas ${ }^{3}$ \\ ${ }^{1,2,3}$ Program Studi Pendidikan Bahasa dan Sastra Indonesia \\ Jurusan Pendidikan Bahasa dan Seni \\ FKIP Universitas Bengkulu \\ loziseptiana@ymail.com
}

\begin{abstract}
Abstrak
Penelitian ini bertujuan untuk mengetahui nilai-nilai kehidupan yang terdapat di dalam novel Moga Bunda Disayang Allah karya Tere Liye. Rumusan masalah penelitian ini adalah bagaimanakah nilai kehidupan yang terdapat di dalam novel Moga Bunda Disayang Allah karya Tere Liye. Metode yang digunakan deskriftif. Pendekatan penelitian yang digunakan dalam penelitian ini adalah pendekatan objektif, yang memusatkan perhatiannya analisis intrinsik, Sumber data penelitian ini adalah novel Moga Bunda Disayang Allah Karya Tere Liye dengan data yang diambil berupa teks-teks dari alur cerita, tema dan amanat cerita, tokoh dan penokohan, sudut pandang, gaya bahasa novel Moga Bunda Disayang Allah Karya Tere Liye. Hasil Penelitian Nilai-nilai kehidupan yang terdapat dalam novel Moga Bunda Disayang Allah adalah, dilihat dari sisi tokoh utama Bunda HK yang sangat menyayangi anaknya yang cacat dania tak henti-henti berjuang melawan penyakit Melati. Karang yang kasar dalam merawat Melati, jelek fisiknya tetapi berhati mulia. Tuan HK kaya tapi tidak manusiawi, salah menilai seseorang dari penampilan fisik, ternyata HK keliru. Karang yang dikucilkan karena penampilannya ternyata dialah yang menyelamatkan putrinya. Dilihat dari tokoh Melati yang depresi, prustasi dengan keterbatasannya, tiba-tiba bisa mendoakan Bundanya "met bobo Bunda. Moga Bunda Disayang Allah".
\end{abstract}

\section{Kata kunci: Nilai Kehidupan, Novel Moga Bunda Disayang Allah, pendekatan objektif}

\begin{abstract}
This study aims to determine the values of life contained in the novel Moga Bunda Disayang Allah by Tere Liye. The formulation of this research problem is how the value of life contained in the novel Moga Bunda Disukai Allah by Tere Liye. The method used is descriptive. The research approach used in this study is an objective approach, focusing on intrinsic analysis. The source of this research data is the novel Moga Bunda Disayang Allah Tere Liye's work with data taken in the form of texts from the story line, theme and story, character and characterization, Point of view, the novel style of Moga Mother Dear Mother God by Tere Liye.Research Results Values of life contained in the novel Moga Mother Dear God is, judging from the main character of Bunda HK who is very fond of his disabled son and he endlessly fight against the disease Melati. Rough corals in caring for Jasmine, ugly physical but noble heart. Mr. HK is rich but inhuman, misjudging someone from his physical appearance, it turns out $\mathrm{HK}$ is wrong. The reef that was ostracized because of his appearance turned out to be the one who saved his daughter. Judging from the depressed Melati characters, the prestation with its limitations, suddenly can pray for Mother "met bobo Mother. Moga Mother Dear God"
\end{abstract}

Keywords: Values life, Novel Moga Bunda Disayang Allah, objective approach 


\section{PENDAHULUAN}

Salah satu bentuk karya sastra adalah novel. Novel adalah karya fiksi yang dibangun melalui berbagai unsur intrinsiknya. Unsur-unsur tersebut sengaja dipadukan pengarang dan dibuat mirip dengan dunia yang nyata lengkap dengan peristiwa-peristiwa didalamnya, sehingga nampak seperti sungguh ada dan terjadi. Unsur inilah yang menyebabkan karya sastra (novel) hadir. Unsur intrinsik sebuah novel adalah unsur-unsur yang membangun karya sastra itu sendiri. Keterpaduan berbagai unsur intrinsik inilah yang membuat sebuah novel berwujud. Novel sebagai salah satu bentuk karya sastra diharapkan memunculkan nilai-nilai positif bagi penikmatnya, sehingga mereka peka terhadap masalah-masalah yang berkaitan dengan kehidupan sosial dan mendorong untuk berprilaku yang baik. Nilai kehidupan dalam sastra adalah sifatsifat (hal-hal) atau merupakan sesuatu yang positif yang berguna dalam kehidupan manusia dan pantas untuk dimiliki tiap manusia.

Dengan memahami novel-novel kita mendapatkan suatu gambaran dari suatu proses (perubahan sosial dan tata nilai), sementara itu juga berarti bahwa perkembangan novel-novel juga merupakan suatu proses yang berpangkal dari (proses) perubahan sosial dan tata nilai itu tadi. Suatu hubungan yang timbal balik dan kait berkait (Esten, 2001 hal:47).

Pemilihan novel "Moga Bunda Disayang Allah karya Tere Liye" dilatar belakangi oleh adanya keinginan untuk memahami nilai-nilai pendidikan yang ada dalam novel ini. Novel Moga Bunda Disayang Allah mempunyai nilai kehidupan positif yaitu penjelasan mengenai nilai pendidikan religius, nilai pendidikan moral dan nilai pendidikan sosial.
Penelitian terdahulu mengenai novel "Moga Bunda Disayang Allah" pernah dilakukan oleh Hesti Rohani, (2014) dengan hasil peneliatian Hasil dari penelitian ini menunjukkan: (1) Nilai-nilai Pendidikan Akhlak yang terkandung dalam novel "Moga Bunda Disayang Allah" adalah akhlak kepada Allah yang meliputi beribadah kepada Allah, berdzikir kepada Allah, ikhlas, syukur kepada Allah dan berdo'a kepada Allah, akhlak kepada diri sendiri yang meliputi pantang menyerah, sabar, pemaaf dan optimis; akhlak kepada sesama manusia yang meliputi menghormati tamu, tolong menolong, empati, dan menghargai orang lain. Selain itu juga terdapat akhlak tercela yang harus kita hindari, yaitu minum-minuman keras dan tak acuh. (2) Terdapat relevansi antara nilai-nilai pendidikan akhlak dalam novel Moga Bunda Disayang Allah dengan Pembelajaran Akidah Akhlak di Madrasah Ibtidaiyah, yaitu adanya kesesuaian. antara nilai pendidikan akhlak yang terkandung dalam novel Moga Bunda Disayang Allah dengan materi akidah akhlak di Madrasah Ibtidaiyah.

Penelitian terdahulu pernah dilakukan oleh Heni Purwatiningsih (2015) Penyajian hasil analisis menggunakan teknik penyajian informal. Hasil penelitian ini disimpulkan bahwa (1) unsur intrinsik meliputi (a) tema: perjuangan hidup; (b) alur: alur maju; (c) latar tempat: kamar Bunda, laut, ruang keluarga,Pulau Mikronesia, dan Pelabuhan, latar waktu: pagi, siang, sore, dan malam hari, latar sosial: keluarga kaya atau kalangan atas; (d) tokoh utama: Melati, tokoh tambahan:Bunda, Karang, Tuan $\mathrm{Hk}$, Kinasih, Salamah, Ibu-ibu Gendut, suster Tya, dokter Ryan, dan Mang Jeje (e) sudut pandang orang ketiga serba tahu; dan (f) amanat tetap berusaha dan berdoa karena sesungguhnya Allah tidak akan 
memberikan cobaan diluar batas kemampuan hamba-Nya; (2) nilai pendidikan dalam novel ini ada tiga, yaitu; (a) nilai pendidikan agama meliputi: beribadah, berdoa, dan bersyukur (b) nilai pendidikan moral meliputi: tidak putus asa, percaya diri, sabar, berpikir logis, pengendalian diri, dan prasangka baik (c) nilai pendidikan sosial meliputi: kasih sayang, penghargaan, kesetiaan, dan memberi semangat.

Sebuah novel mengandung dan menawarkan pesan moral itu salah satu, dua dan ketiganya sekaligus masingmasing dengan wujud rinci khusunya" (Nurgiyantoro, 2013:324) Mengenai pesan moral ketaatan dalam beribadah Salam (2000:193) mengemukakan bahwa itu merupakan salah satu dari 12 (dua belas) dimensi kewajiban manusia dalam kristalisasi akhlak yang baik. Atas segala rahmat-Nya manusia jelas berutang budi yang besar, Dialah yang wajib diibadahi dan ditaati oleh segenap manusia maka sudah sepatutnya apabila manusia berterima kasih atas segala pemberian-Nya dengan salah satu cara diantaranya, yaitu taat.

Sedangkan mengenai nilai-nilai kehidupan, dalam novel tersebut menceritakan tentang seseorang bernama Karang yang berusaha mengajarkan metode pembiasaan kepada anak yang bisu, tuli, dan buta yang pertama kalinya diajarkan tentang sendok dan garpu,walaupun ditentang oleh ayahnya. Dengan adanya permasalahan tentang materi dan metode di atas, penulis akan mengkaji media cetak berbentuk karya sastra, yaitu novel, berjudul "Moga Bunda Disayang Allah karya Tere-Liye".

Nilai-nilai religiusitas dalam novel sangat penting untuk diteliti.Hal ini disebabkan nilai religius merupakan nilai yang sangat pribadi bagi seseorang bukan saja menyangkut hubungan mendasar antara individu dengan Tuhannya, namun juga bagaimana hubungan manusia dengan alam sekitarnya sebagai perwujudan dan sikap religius seseorang. Oleh karena itu akan mempengaruhi segala perilaku dan dan perbuatan orang orang itu dalam kehidupan sehari-hari. Nilai religius adalah norma keagamaan yang dipegang seseorang sebagai pedoman dalam hidupnya.Analisis terhadap novel Moga Bunda Disayang Allah dibatasi pada kutipan-kutipan yang mengandung nilai-nilai Islam. Berdasarkan nilai-nilai religiusitas karena setelah membaca novel Moga Bunda Disayang Allah, ditemukan kutipan-kutipan yang mengandung nilai-nilai Islam yang digunakan pengarang dalam menyampaikan isi novel Moga Bunda Disayang Allah. Kajian tersebut juga akan dikaitkan dengan pembelajaran sastra, khususnya unsur intrinsik dan ekstrinsik novel.

Novel yang terbit pada tahun 2006 ini merupakan salah satu novel best seller karya Tere Liye. Novel ini menawarkan kisah segar dan banyak sekalipesan moral yang terkandung di dalamnya. Sehingga diangkat ke layar lebar dengan sutradara Jose Poernomo dan dibintangi oleh Fedi Nuril dan Shandy Aulia. Novel ini mengajarkan kita bagaimana bersyukur, ikhlas dan tabah dalam menjalani takdir hidup yang telah ditetapkan oleh sang Maha Pencipta. Ini dapat dilihat bagaimana kesabaran dan ketabahan bunda HK, ibunda Melati dalam menerima takdir hidup putri semata wayangnya, terus berdoadan mengadu pada sang Khalik, memohon kemudahan bagi putrinya di sepertiga malam dantak pernah putus asa selalu mencari jalan keluar untuk kesembuhan melati, berbagai dokter didatangkan baik dari dalam maupun dari luar negeri demi putri yang dicintainya.

Peneliti akan mengkaji novel Moga Bunda Disayang Allah karena, dalam novel tersebut terdapat nilai-nilai kehidupan 
yang didapat hikmahnya. Dalam novel tersebut Tere-Liye menyampaikan pesan kesabaran yang dapat memberi pencerahan melalui tokohnya kepada pembaca sehingga dapat diambil hikmah dengan mencontoh sifat baik dan meninggalkan sifat buruk. Novel ini mengajak pembaca untuk mengasah ketajaman spiritual tentang keikhlasan dalam menerima kenyataan dari Allah dan mencoba untuk tidak terus menerus tenggelam dalam lumpur penyesalan.

\section{METODE}

Metode yang digunakan dalam penelitian ini adalah metode kualitatif. Penelitian kualitatif menurut (Bogdan dan Taylor dalam Moleong, 1991:3) adalah prosedur penelitian yang menghasilkan data deskriptif berupa kata-kata tertulis atau lisan dari orang-orang dan pelaku yang dapat diamati oleh peneliti. Tujuan dari penelitian ini adalah untuk membuat deskriptif, gambaran, atau lukisan secara sistematis, faktual, dan akurat mengenai fakta-fakta, sifat-sifat serta hubungan antar fenomena yang diteliti.

Metode kualitatif digunakan karena sesuai dengan objek penelitian sekaligus sumber data yaitu novel Moga Bunda Disayang Allah Karya Tere Liye. Jadi, dalam penelitian ini, metode kualitatif difungsikan untuk memaparkan data maupun hasil analisis data dengan menggunakan kata-kata ataupun kalimat dan bukan dalam bentuk angka-angka agar dapat memecahkan masalah mengenai nilai kehidupan yang terkandung dalam novel Moga Bunda Disayang Allah Karya Tere Liye.

Dalam penelitian ini peneliti menggunakan pendekatan struktural atau yang sering disebut dengan pendekatan objektif. Pendekatan struktural atau objektif berpusat pada unsur intrinsik karya sastra. $\begin{array}{lrr}\quad \text { Menurut } & \text { Teeuw } & \text { (1984:135), } \\ \text { pendekatan } & \text { struktural } & \text { mencoba } \\ \text { menguraikan } & \text { keterkaitan } & \text { dan fungsi }\end{array}$ masing-masing unsur karya sastra sebagai kesatuan struktural yang bersama-sama menghasilkan makna menyeluruh. Pendekatan struktural membongkar seluruh isi (unsur-unsur intrinsik di dalam novel) dan menghubungkan relevansinya antara unsur-unsur di dalamnya.

Data yang digunakan dalam penelitian ini adalah nilai kehidupan dalam novel Moga Bunda Disayang Allah karya Tere Liye. Sumber data dalam dalam penelitian ini ialah Moga Bunda Disayang Allah karya Tere Liye cetakan XIX, Republika penerbit, Jakarta Selatan tahun 2013, terdiri dari 306 halaman.

Dalam penelitian ini, peneliti sendiri sebagai instrumen penelitian. Pada hakikatnya penelitian ini merupakan hasil interaksi peneliti dengan karya sastra yang dianalisis. Untuk memudahkan pengumpulan data, maka peneliti menggunakan teknik daftar data. Langkahlangkah pengumpulan data dilakukan dengan tahapan sebagai berikut :

1. Membaca keseluruhan novel Moga Bunda Disayang Allah karya Tere Liye, untuk memperoleh pemahan menyeluruh atas nilai-nilai pendidikan karya yang dianalisis.

2. Membaca ulang novel Moga Bunda Disayang Allah karya Tere Liye dengan menandai bagian novel yang menyatakan nilai-nilai kehidupan dengan menggaris bawahi.

3. Mengumpulkan bagian-bagian karya sasta yang merupakan nilai-nilai kehidupan cerita pada lembar pencatatan data bentuk daftar.

Untuk merealisasikan metode dan pendekatan yang digunakan dalam menganalisis, penulis menempuh langkah-langkah sebagai berikut: 
1. Membaca secara cermat dan teliti seluruh isi novel Moga Bunda Disayang Allah Karya Tere Liye.

2. Membuat sinopsis novel Moga Bunda Disayang Allah KaryaTere Liye.

3. Mengelompokan atau mengklasifikasikan nilai-nilai kehidupan dalam novel Moga Bunda Disayang Allah karya Tere Liye ke dalam kategori aspek nilai-nilai kehidupan.

4. Mendeskripsikan nilai-nilai kehidupan dalam novel Moga Bunda Disayang Allah karya Tere Liye.

5. Menafsirkan nilai-nilai kehidupan dalam novel Moga Bunda Disayang Allah karya Tere Liye.

6. Mengambil kesimpulan penelitian.

\section{HASIL DAN PEMBAHASAN}

\section{Sinopsis Novel}

Dalam

Novel ini diceritakan

seorang anak bernama Melati penderita buta dan tuli untuk bisa mengenali dunia, dan juga perjuangan seorang Pemuda bernama Karang untuk bisa keluar dari perasaan bersalah setelah kematian 18 anak didiknya dalam kecelakaan kapal. Melati bocah berusia 6 tahun yang buta dan tuli sejak dia berusia 3 tahun. Selama 3 tahun ini dunia melati gelap. Dia tidak memiliki akses untuk bisa mengenal dunia dan seisinya. Mata, telinga semua tertutup baginya. Melati tidak pernah mendapatkan cara untuk mengenal apa yang ingin dikenalnya. Rasa ingin tahu yang dipendam bertahun tahun itu akhirnya memuncak, menjadikan Melati menjadi frustasi dan sulit dikendalikan. Melati hanya bisa mengucap Baa dan Maa. Orang tuanya berusaha berbagai macam cara untuk bisa mengendalikan Melati. Bahkan tim dokter ahli yang diundang oleh orang tuanya tidak berhasil mengendalikan Melati.

Pak Guru karang, seorang pemuda yang suka mabuk dan sering bermurung diri dikamar rumah ibu gendut yang akhirnya menjadi guru Melati. Karang sebenarnya hampir kehilangan semangat hidupnya setelah 18 anak didiknya tewas dalam kecelakaan perahu. Perasaan bersalahnya hampir setiap hari menghantuinya selama 3 tahun terakhir. Dia bahkan hampir tidak berminat ketika ibunya Melati memintanya untuk membimbing Melati. Tapi demi cintanya terhadap anak-anak Karang akhirnya datang memenuhi permintaan ibunya Melati.

Tidak mudah untuk menemukan metode pengajaran bagi Melati. Bagaimana caranya Melati bisa mendengar apa yang dikatakan Karang? Bagaimana caranya Melati bisa melihat? Bahkan untuk menangis saja Melati tidak bisa menemukan kosakata yang benar. Dunia Melati benar-benar gelap. Melati tidak mempunyai akses untuk tahu. Tidak mempunyai cara untuk mengenal apa yang ingin dia kenal. Setiap kali ada yang menyentuh tubuh Melati maka dia akan marah, mengamuk dan melemparkan apa saja yang tercapai oleh tangannya.

Karang hampir putus asa.Lalu keajaiban datang ketika air mancur membasuh lembut telapak tangan Melati. Melati merasakan aliran air di sela jemarinya. Saat itulah untuk pertama kalinya Karang melihat Melati tertawa.Karang akhirnya mengerti, melalui telapak tangan itulah Karang menuliskan kata Air, dan meletakkan telapak tangan Melati kemulutnya dan berkata A-I-R. Melati akhirnya mengerti benda yang menyenangkan itu bernama air. Melalui telapak tangan Melati, air mancur yang mengalir di tangan dan sela-sela jarinya berhasil mencukilnya. Melalui telapak tangan itulah semua panca indera disitu. Akhirnya dunia Melati tidak lagi gelap. Dia bisa mengenali orang tuanya, dia bisa mengenali kursi, sendok, pohon dan sebagainya.

Kisah ini diakhiri dengan pamitnya Karang dari rumah keluarga HK. Mesti 
terlihat kesedihan dari Melati, karena akan ditinggal gurunya yang selalu membimbing dan mendongeng untuknya. Untuk menghilangkan kekesalan melati melepas ayam kate dengan Mang Jeje. Ucapan terimakasih dan doa Melati mengiringi kepergian Karang. Keluarga HK juga terima kasih kepada pemuda mantan pemabuk itu. Berkat jasanya, setidaknya anak semata wayangnya dapat mengenal dunia.

\section{Analisis Struktur Novel Moga Bunda Di Sayang Allah Karya Tere Liye}

\section{Unsur Pembangun}

\section{Tema}

Novel ini menyampaikan persoalan hidup dan kehidupan, persoalan manusia dan kemanusiaan seorang Bunda yang memperjuangkan kesembuhan anaknya.

Persoalan Bunda HK tersebut adalah bagaimana cara mengobati Melatiyang kehilangan indera pengelihatandan pendengarannya pada saat usianya baru 3 tahun.awalnya dia sangat periang dan lucu, melati mulai buta dan tuli sejak dia berusia 3 tahun. Selama 3 tahun ini dunia melati gelap. Dia tidak memiliki akses untuk bisa mengenal dunia dan seisinya. Mata, telinga dan semua tertutup baginya. Melati tidak pernah mendapatkan cara untuk mengenal apa yang ingin dikenalnya. Rasa ingin tahu yang dipendam bertahun tahun itu akhirnya memuncak, menjadikan Melati menjadi frustasi dan sulit dikendalikan.

Kaki anak berusia sekitar tiga tahun itu lincah berlarian. Tadi takut-takut menyentuh buih ombak yang menjilat-jilat bibir pantai. Setelah brhasil menyentuhnya, malah tertawa senang. Ternyata menyenangkan. Ternyata tidak menakutkan seperti yang ia duga.

Waktu seolah berhenti ketika melihatnya...

"JDUT!"Brisbee, piringan terbang berwarna merah itu entah dari mananya, tiba-tiba sudah menghantam dahinya. Memutus semua kesenangan. Seketika. Menghentikan seluruh tawa (Liye,2006:64). Ketika mereka tahu bahwa anak semata wayangnya buta, tuli dan bisu perasaan mereka sangatlah sedih. Mereka sudah merasa putus asa. Mereka berusaha berbagai macam cara untuk bisa mengendalikan Melati. Bahkan tim dokter ahli yang diundang oleh mereka juga tidak berhasil mengendalikan Melati. Tapi yang mereka dapatkan hanyalah kata-kata yang menyakitkan.

Sampai akhirnya Kinasih menyarankan agar Bunda HK meminta bantuan kepada pemuda yang bernama Karang. Sudah beberapa kali Bunda HK mengirimkan surat, tapi karang sama sekali tidak menghiraukan surat-surat itu.Pada akhirnya Bunda HK sendiri yang mendatangi Karang kerumahnya, Bunda sangat memohon kepada Karang agar dia bisa membantu Melati. Bunda tidak tahu lagi harus minta bantuan kepada siapa lagi, semua dokter-dokter yang ahli sudah didatangkannya tapi tidak ada juga hasilnya. Bunda sangat berharap Karang dapat membantu anaknya.Tapi Karang malah menjawab dengan kasar, "dokter saja tidak mampu menangani anak Ibu, apalagi saya". Bunda sangat sedih mendengar perkataan Karang, tapi Bunda tidak berhenti disitu.Bunda memohon lagi kepada Karang. "saya mohon anakku bantulah putri kami, kamulah harapan kami satu-satunya."Bunda pun pulang dan berharap Karang berubah pikiran.

\section{Amanat}

Dari tema yang disampaikan pengarang itu, pesan yang disampaikan adalah:

Dalam hidup ini kita pasti mempunyai masalah. Masalah dan ujian yang Allah beri kepada kita melainkan untuk menguji keimanan kita dan ibadah. Novel ini mengajarkan kita untuk tidak 
mudah putus asa dalam menghadapi segala ujian, karena setiap ujian pasti ada jalan keluarnya. Allah tidak akan memberikan ujian kepada umatnya melampaui batas kemampuannya. Kita juga harus senantiasa bersyukur atas segala nikmat yang telaah Allah berika kepada kita, harus menghargai orang lain dan saling percaya.

\section{Gambaran Tokoh}

Seperti disebut sebelumnya, tema novel Moga Bunda Disayang Allah adalah "perjuangan Bunda menghadapi masalahketerbatasan anaknya".Maka untuk memahami nilai-nilai kehidupan dalam novel ini harus dilihat dari persoalan yang diungkapkan pengarang.

\section{Tokoh Bunda HK}

Seperti yang dibuat sebelumnya, tokoh Bunda HK adalah tokoh yang banyak diceritakan, tokoh yang paling banyak menderita batin, tokoh yang paling banyak berjuang demi anaknya, tokoh yang paling sabar mengahadapi penderitaan anaknya.

Bunda HK adalah bunda Melati, seorang perempuan yang sabar, tabah dan penyayang, dia mempunyai seorang anak bernama Melati yang buta, tuli dan bisu. Awalnya anaknya itu seorang putri yang ceria dan manja semenjak tiga tahun lalu, saat bermain ditepi pantai anaknya terkena piringan terbang dan hilang semua keceriaan itu. Sejak mengetahui kalau anaknya cacat total perasaan Bunda sangat sedih. Bunda selalu sabar menghadapi anaknya yang semakin hari semakin menjadi-jadi.Bunda selalu berjuang demi kesembuhan anaknya. Bunda juga tak henti-hentinya berdoa kepada Allah agar anaknya bisa sembuh.Dari dokter biasa sampai dokter yang ahli sudah Bunda datangkan untuk membantu anaknya, tapi tidak juga berhasil. Bunda hanya mendapatkan perkataan yang tidak menyenangkan dari dokter dan orangorang ahli, mereka mengatakan kalau anaknya itu gila. Mendengar kata-kata itu pastinya sangat menyakitkan perasaan Bunda. Bunda tidak tahu harus minta bantuan kepada siapa lagi, semua dokterdokter yang ahli sudah didatangkannya tapi tidak ada juga hasilnya. Setiap hari Bunda HK mengirimi Karang surat, tapi tak ada jawaban.Bunda sangat berharap Karang dapat membantu anaknya.Tapi Karang tidak mnghiraukan Bunda HK. Bunda HK menemui Karang dirumahnya, waktu Bunda HK melihat Karang, Bunda langsung terkejut melihat kondisi Karang yang jorok, semerawut dan sama sekali tidak menggambarkan kalau dia itu malaikatnya anak-anak. Bunda HK berpikir apa benar ini Karang yang Kinasih maksud, apa saya tidak salah rumah?. Tapi inilah kenyataannya, ini benar-benar Karang. Meskipun penampilan Karang seperti itu hati nurani Bunda HK percaya kalau Karang bisa membantu anak semata wayangnya.

Akhirnya Karang berubah pikiran dia datang kerumah Bunda HK, dia ingin mencoba membantu Melati.Namun belum juga ada hasilnya. Tapi sesabar-sabarnya manusia juga pasti akanada batasnya. Itulah yang dialami Bunda HK.Bunda HK sudah putus asa karena putri semata wayangnya tak kunjung ada perubahan. Bunda HK pasrah dengan takdir yang telah diberikan kepadanya.

"Berjuanglah, Anakku! Bunda mohon. Jangan menyerah! Bunda berbisik senyap. Tertunduk. (hlm. 83).

"kau mungkin benar, Anakku. Janjijanji itu juga mungkin benar....tapi aku sudah amat lelah...sudah amat peenat...setiap malam bersimpuh, beerharap, mengirimkan beribu kata doa, tapi tetap tak kunjung ada kabar baiknya. Mungkin semua memang harus berakhir seperti ini..." bunda menahan sedan tangisnya. (hal. 170)

2. Tokoh Tuan HK

Tokoh Tuan HK adalah tokoh yang pekerja keras, tokoh yang penyayang, 
tokoh yang baik, dan tokoh yang tidak manusiawi.

Tuan HK sangat menyayangi anak dan istrinya.Tuan HK juga pekerja keras, setiap bulan dia pasti keluar Negeri untuk kerja.Tuan HK sangat membenci orang yang bertindak kasar terhadap anaknya dan dia juga tidak menyukai orang yang pemabuk. Tuan HK sangat tidak menyukai Karang, karena Karang kasar dan pemabuk selain itu penampilan Karang juga semerawut. Tuan HK melihat Karang hanya dari penampilan luarnya saja. Tuan HK hanya melihat seseorang dari sisi ekonomi.

"KAU! SIAPA PUN KAU! PERGI DARI RUMAH INI!"

Tuan HK kehabisan kalimat mendengar jawaban dingin Karang. Apa barusan dibilang? Mengajarinya?Ringan sekali pemuda ini mengatakan kalimat itu. Omong kosong! Bagaimana mungkin dia membiarkan ada orang sinting masuk ke ruang makannya?Pelipis Tuan HK bergerakgerak menahan amarah."

\section{Tokoh Karang}

Karang adalah tokoh yang kasar, tokoh yang keras, tokoh yang tangguh, tokoh yang jorok, tokoh yang paling dibenci Tuan HK. Seorang pemuda yatim piatu dan miskin.

Dulu Karang mempunyai taman bacaan untuk anak-anak yang gemar membaca. Ketika Karang dan anak-anak muridnya berlibur, kapal yang mereka tumpangi karam dan 18 anak muridnya meninggal. Sejak kejadian itulah Karang lebih suka menyendiri, tidak suka mengurus badan dan sukanya mabukmabukkan. Dia sangat jorok Sikapnya juga sekarang sangat kasar dan keras. Dia memang orangnya keras, kasar dan semaunya sendiri. Awalnya dia tidak mau membantu Melati, tetapi entah kenapa dia berubah pikiran.A khirnya Karang datang ke kediaman Tuan Hk dan Bunda HK. Karang sangat kasar membantu Melati. Tapi disisi lain dia memiliki sifat yang tangguh. Meskipun dia dibenci, dihina Tuan HK dan diusir dari rumah mereka. Dia memohon waktu 21 hari kepada Bunda HK. Dia yakin kalau dia bisa membantu Melati, dia tetap bertahan dan tetap ingin membantu. Jika didalam waktu 21 hari tidak juga ada perubahan dari Melati dia yang akan pergi sendiri dari rumah itu. Memang jelek fisiknya tapi mulia tujuannya.

"Benarlah. Jika kalian sedang bersedih, jika kalian sedang trpagut masa lalu menyakitkan, penuh penyesalan seumur hidup, salah satu obatnya adalah dengan menyadari masih banyak orang lain yang tidak lebih beruntung dibanding kita. Itu akan memberikan pengertian bahwa hidup ini belum berakhir. Itu akan membuat kita selalu meyakini setiap satu mahkluk berhak atas satu tujuan." (hal.172)

\section{Tokoh Kinasih}

Tokoh Kinasih adalah tokoh yang baik, tokoh yang ramah.Kinasih adalah mantan kekasihnya Karang, dia anaknya Dokter Ryan dan dia juga Dokter. Dia sangat menyayangi Melati. Dia selalu menyemangati Bunda HK agar tidak mudah menyerah menghadapi keterbatasan Melati. Dia juga yakin kalau Melati itu bisa disembuhkan.

"Melati akan baik-baik saja, Bun...jika Bunda tetap yakin, maka ia pasti akan baik-baik saja."Kinasih berbisik pelan. Tersenyum. Memotong cerita dua hari lalu. Mencoba membesarkan hati."

5. Tokoh Salamah

Tokoh Salamah adalah tokoh yang baik, tokoh yang setia.

Setiap pagi Salamah menyiapkan sarapan untuk keluarga Tuan HK. Dia sangat setia kepada keluarga Tuan HK, Dia tetap ingin kerja di sana. Dia ingin bersama keluarga Tuan HK. Saking setianya dia tidak menikah, karena dia takut kalau dia menikah suaminya akan menyuruhnya berhenti jadi pembantu keluarga Tuan HK. 


\section{Tokoh Melati}

Tokoh Melati adalah tokoh yang periang, tokoh yang manja, tokoh yang depresi, tokoh yang pintar, tokoh yang jahil.

Melati dulunya adalah anak yang ceria. Tetapi sejak kejadian 3 tahun silam, disaat dia bermain dipantai bersama keluarganya tiba-tiba dia terkena piringan terbang dia terjatuh dan terputus semua kegembiraan. Mulai sejak itulah Melati menjadi anak yang pembrontak. Siapa yang coba-coba memegangnya, dia akan membrontak dan akan membanting semua yang dapat diraihnya. Anak yang sudah tidak ada lagi harapan, bahkan dokter sudah mengatakan dia gila. Tiba-tiba bisa mendoakan bundanya dan mengatakan "met bobo Bunda, moga Bunda Disayang Allah"

\section{Tokoh Suster Tya}

Tokoh yang baik perawatnya Melati. Dia perawat yang baru jadi tidak mengerti aturan mainnya.Suster Tya mencoba membantu Melati makan pakai tangan yang bagus tapi Melati malah membanting piringnya. Dia menjaga Melati dengan baik, tapi karena tidak tahan dngan tingkah laku Melati yang selalu membrontak akhirnya Suster Tya berhenti bekerja.

"Ayo, Melati...pakai tangan bagus!" suster Tya sekali lagi berusaha membantu Melati. Memegang tangan Melati, berusaha mengajari cara menyuap yang baik. la perawat yang baru, jadi tidak terlalu mengerti aturan mainnya." (Hal.56)

8. Tokoh Ibu-Ibu Gendut

Ibu-ibu Gendut adalah tokoh yang baik, tokoh yang sabar, tokoh yang ramah.lbu-ibu Gendut adalah ibu angkatnya Karang. Dia sangat sayang terhadap Karang meskipun Karang hanya anak angkatnya. Dia selalu sabar menghadapi tingkah laku Karang yang keras, acuh, dan cuek terhadapnya. Meskipun sikap Karang sangat tidak mnyenangkan, namun tidak membuat IbuIbu Gendut brubah, dia tetap menyayangi Karang.Karena dia tahu kenapa Karang seperti itu, Karang masih terpukul dengan meninggalnya ke 18 anak muridnya. Ibuibu Gendut juga selalu meyakinkan Karang agar Karang dapat membantu Melati.

"ibu-ibu gendut tertawa pelan, "tidak. Kau bukan orang lain bagiku Karang!" (hal.59)

"Ibu-ibu gendut menelan ludah, berkata pelan, " Kau tahu, ada anak yang memerlukan bantuanmu, Karang. Surat itu bilang.

Mereka membutuhkanmu...."(hal.6)

9. Tokoh Dokter Ryan

Tokoh Dokter Ryan adalah tokoh yang ramah. Dia adalah dokter keluarganya Tuan HK. Dokter Ryan mengenal Karang pemuda yang hebat, Karang sendirian menampung anak jalanan. Membuat sekolah informal. Menjanjikan masa depan bagi mereka. Percaya sekali janji kehidupan yang lebih baik akan datang dari anak-anak berikutnya. Dokter Ryan sangat bangga melihat Karang, Meskipun Karang tidak memiliki pendidikan akademis mendidik anak-anak, tetapi Karang bisa mendidik anak-anak menjadi hebat.

"Untuk ukuran seseorang yang tidak memiliki pendidikan akademis mendidik anak-anak, kau benar-benar hebat, Karang! Aku tersanjung bisa bertemu danganmu." Dokter Ryan tersenyum.

10. Tokoh Mang Jeje

Adalah tokoh yang baik, tokoh yang setia terhadap keluarga Tuan HK. Selama tiga tahun mang jeje selalu memotong rumput yang ada dihalaman rumah membuat halaman rumah Tuan HK indah setiap hari.Dan supaya Melati bisa bermain di atasnya sepanjang hari.

\section{Nilai Kehidupan}

a. Nilai Kesabaran 
Dalam Novel Moga Bunda

Disayang Allah Karya Tere Liye ini nilai kesabaran terdapat pada tokoh Bunda HK. Dengan berbagai upaya telah Bunda HK lakukan untuk kesembuhan Melati, baik mengikuti pengobatan berbagai dokter maupun ahli terapi lainnya namun belum juga ada kemajuan dari Melati. Meskipun belum ada kemajuan dari Melati Bunda terus berjuang dan tak hentihentinya berdoa untuk kesembuhan anaknya. Setiap hari Bunda HK selalu sabar mengahadapi anaknya yang setiap kali disuruh makan, bukannya makan, Melati hanya mengacak-acak makanannya dan membanting semuanya.

b. Nilai Relegius

Didalam Novel Moga Bunda Disayang Allah Karya Tere Liye ini nilai relegius terdapat pada tokoh Bunda HK.Setiap malam Bunda selalu berdoa memohon kepada yang Maha Esa untuk kesembuhan Melati anak semata wayangnya agar bisa merasakan kebahagiaan seperti anak lain rasakan.

c. Nilai Tolong-Menolong

Dalam Novel Moga Bunda Disayang Allah Karya Tere Liye ini nilai tolong-menolong terdapat pada tokoh Karang. Akhirnya Karang mau menolong Melati yang buta, tuli, dan bisu. Karang selalu berusaha membantu Melati agar dia bisa merasakan kebahagiaan yang anak lain bisa rasakan. Karang memohon dan meminta waktu 21 hari kepada Bunda agar dia bisa membantu Melati. Karang berjanji dia akan berubah menjadi lebih baik lagi, tidak ada kekasaran dan minuman keras lagi. Kalau selama 21 hari Melati belum juga ada perubahan, Karang sendiri yang akan pergi dari rumah itu.

d. Nilai Pekerja Keras
Dalam Novel Moga Bunda Disayang Allah Karya Tere Liye ini nilai pekerja keras terdapat pada tokoh Tuan HK. Tuan HK selalu bepergian keluar kota untuk bekerja. Sampaisampai Tuan HK kurang memperhatikan keadaan anaknya. Setiap sebulan sekali Tuan HK selalu keluar kota bahkan keluar negeri.

e. Nilai Kesetiaan

Dalam Novel Moga Bunda Disayang Allah Karya Tere Liye ini nilai kesetiaan terdapat pada tokoh Salamah pembantu Tuan HK dan Bunda HK. Salamah sangat setia terhadap keluarga Tuan HK, sampaisampai dia tidak memikirkan untuk menikah. Dia hanya inigin bersama keluarga Tuan HK.

f. Nilai Pendidikan

Dalam Novel Moga Bunda Disayang Allah Karya Tere Liye ini nilai pendidikan terdapat pada tokoh Kinasih dan Karang.

Kinasih orangnya pintar, dan dia menjadi dokter seperti ayahnya, sedangkan Karang seorang anak yatim piatu yang diangkat anak oleh sepasang suami istri yang mempunyai taman bacaan. Karang salah satu dari murid taman bacaan itu. Karang tumbuh menjadi anak yang sangat membanggakan. Dia melanjutkan pendidikannya keluar ibukota.

\section{Nilai Kehidupan Yang Terkandung Dalam Novel Moga Bunda Disayang Allah Karya Tere Liye}

Nilai kehidupan yang terkandung dalam novel Moga Bunda Disayang Allah dengan kegigihan yang dimiliki oleh Bunda dalam memperjuangkan kesembuhan Melati. Tuan HK yang kurang peduli terhadap Melati. Dengan melakukan berbagai upaya penyembuhan, baik mengikuti pengobatan berbagai dokter maupun ahli terapi lainnya. Hal ini 
mengajarkan nilai-nilai perjuangan dalam menjalani pengobatan untuk terus berusaha dan berjuang dalam menjalani pengobatan, meskipun hasilnya belum memadai namun Bunda HK terus berjuang dan diusahakan untuk penyembuhan. Akhirnya Kinasih menyarankan Bunda untuk mendatangkan guru privat, yaitu Karang. Bunda berharap Karang bisa menyembuhkan Melati. Awalnya Karang menolak permohonan Bunda, tapi akhirnya Karang berubah pikiran dia mau membantu Melati. Melati selalu saja memberontak dan menolak untuk diajari. Karang sangat kasar membantu Melati, selain kasar Karang juga pemabuk. Melihat Karang yang kasar dan ternyata juga pemabuk, Tuan HK dan Bunda HK mengusir Karang. Tapi Karang tidak ingin pergi, dia ingin tetap membantu Melati. Karang memohon dan meminta waktu 21 hari kepada Bunda agar dia bisa membantu Melati. Karang berjanji dia akan berubah menjadi lebih baik lagi, tidak ada kekasaran dan minuman keras lagi. Kalau selama 21 hari Melati belum juga ada perubahan, Karang sendiri yang akan pergi dari rumah itu. Pada awalnya Karang kesulitan untuk mengajari Melati. Karena itu Karang mencari cara untuk dapat berkomunikasi dengan Melati. Tidak sengaja Karang melihat Melati sedang bermain air dihalaman rumah, dan disitulah Karang tau kalau Melati bisa merasakan sesuatu melalui telapak tangannya. Dengan cara tersebut, akhirnya Karang bisa membantu Melati menghubungkan kedunianya lagi. Akhirnya Melati dapat pulih. Bahkan anak yang bisu, tuli dan buta dan dianggap gila itu bisa mendoakan ibunya "met bobo Bunda...Moga Bunda Disayang Allah" sebuah doa yang tidak terduga.

\section{PENUTUP}

\section{Kesimpulan}

Melati yang sebelumnya ceria tiba-tiba bisu, tuli, dan buta akibat terkena piringan terbang. Melati menjadi anak yang prustasi dan pemberontak. Bunda HK berjuang untuk kesembuhan anaknya. Suatu ketika Bunda sampai merasa putus asa. Dalam keputus asaan itu ada yang menyarankan untuk meminta bantuan Karang. Karang semula menolak yang alasannya dokter saja tidak bisa menyembuhkan apalagi dia. Tapi Karang berubah pikiran, ia mengabulkan permintaan Bunda HK. Namun persoalan belum selesai, Tuan HK yang tidak menyukai Karang karena pemabuk, jorok, kasar, Karang diusir.Tapi Karang memohon bahkan sampai seperti mengemis agar diberi waktu dmi kesembuhan Melati. Akhirnya Melati dapat pulih. Bahkan anak yang bisu, tuli dan buta dan dianggap gila itu bisa mendoakan ibunya "met bobo Bunda...Moga Bunda Disayang Allah" sebuah doa yang tidak terduga. Dan doa itu dijadikan judul novel oleh pengarang.

Nilai-nilai kehidupan yang terdapat dalam novel Moga Bunda Disayang Allah adalah:

1. Dilihat dari sisi tokoh utama Bunda HK yang sangat menyayangi anaknya yang cacat dania tak henti-henti berjuang melawan penyakit Melati.

2. Dilihat dari sisi tokoh Karang yang kasar merawat Melati, meskipun jelek fisiknya tetapi ia berhati mulia.

3. Dilihat dari tokoh Tuan HK yang kaya tidak manusiawi. la salah menilai seseorang dari penampilan fisik, ternyata HK keliru. Karang yang dikucilkan karena penampilannya ternyata dialah yang menyelamatkan putrinya.

4. Dilihat dari tokoh Melati yang depresi, prustasi dengan keterbatasannya, tibatiba bisa mendoakan Bundanya "met bobo Bunda...Moga Bunda Disayang Allah"

5. Dilihat dari tokoh Kinasih yang saying kepada Melati danselalu meyakinkan Bunda HK. 
6. Dilihat dari tokoh Salamah yang selalu setia kepada Keluarga Tuan HK, sehingga dia tidak ingin menikah.

7. Dilihat dari tokoh Ibu-Ibu Gendut yang sangat menyayangi Karang, meskipun Karang hanya anak angkatnya dan dia selalu membujuk Karang agar Karang mau membantu Melati.

8. Dilihat dari tokoh Dokter Ryan yang sangat bangga melihat Karang, Meskipun Karang tidak memiliki pendidikan akademis mendidik anakanak, tetapi Karang bisa mendidik anak-anak menjadi hebat.

9. Dilihat dari tokoh Tya yang sayang kepada Melati.

10. Dilihat dari tokoh Mang Jeje yang setia kepada keluarga Tuan HK.

\section{Saran}

1. Novel Moga Bunda Disayang Allah dapat digunakan sebagai referensi bagi penenliti lain untuk melanjutkan penelitian yang lebih dikembangkan khusunya nilai khidupan karena novel ini banyak mengandung nilai-nilai kehidupan.

2. Bagi para penulis hendaknya selalu memasukan nilai-nilai kehidupan yang bermanfaat agar karyanya tidak hanya berguna sebagai hiburan saja namun juga dapat dimanfaatkan sebagai media edukasi.

3. Bagi pembaca, novel sangat disaranakan karena banyak menceritakan kehidupan sosial dan banyak memberikan nilai-nilai kehidupan.

\section{DAFTAR PUSTAKA}

Esten, Mursal. 1985. Kesusastraan Pengantar Teori dan Sejarah. Bandung: Sinar Baru Algesindo.

Liye, Tere. 2006 Moga Bunda Disayang Allah. Jakarta Selatan: Republika Penerbit University Press.

Moleong, Lexi. 1991. Metode Penelitian Kualitatif. Bandung: Remaja Rosdakarya.

Nurgiyantoro, Burhan. 2013. Teori Pengkajian Fiksi. Yogyakarta: Gadjah Mada.

Salam. 2000. Kritik Sastra Indonesia Modern. Yokyakarta. Gama Media.

Teeuw, A. 1984. Sastra dan Ilmu Sastra: Pengantar Teori Sastra. Jakarta: Pustaka Jaya. 